\title{
Absence of Inferior Gluteal Artery: A Rare Observation
}

\author{
Ausencia de la Arteria Glútea Inferior: Una Rara Observación \\ Sreenivasulu Reddy; Venkata Ramana Vollala \& Mohandas Rao
}

REDDY, S.; RAMANA, V. V. \& RAO, M. Absence of inferior gluteal artery: A rare observation. Int. J. Morphol., 25(1):95-98, 2007.

SUMMARY: The gluteal region is an important anatomical and clinical area which contains muscles and vital neurovascular bundles. They are important for their clinical and morphological reasons. In this manuscript we report a rare case of absence of inferior gluteal artery. In the same specimen the superior gluteal artery was taking origin from the anterior division of internal iliac artery. The structures normally supplied by the inferior gluteal artery were supplied by a branch coming from the superior gluteal artery. The developmental and clinical significance of the anatomical variation is discussed.

KEY WORDS: Internal iliac artery; Inferior gluteal artery; Superior gluteal artery; Anatomical variation.

\section{INTRODUCTION}

Normally, the internal iliac artery begins at the common iliac bifurcation, at the level of sacroiliac joint. It descends posteriorly to the superior margin of the greater sciatic foramen where it divides into an anterior trunk and a posterior trunk. The branches arising from the posterior trunk include iliolumbar artery, lateral sacral arteries and superior gluteal artery. The anterior trunk gives superior vesical artery, inferior vesical artery, middle rectal artery, vaginal artery, obturator artery, uterine artery, internal pudendal artery and inferior gluteal artery.

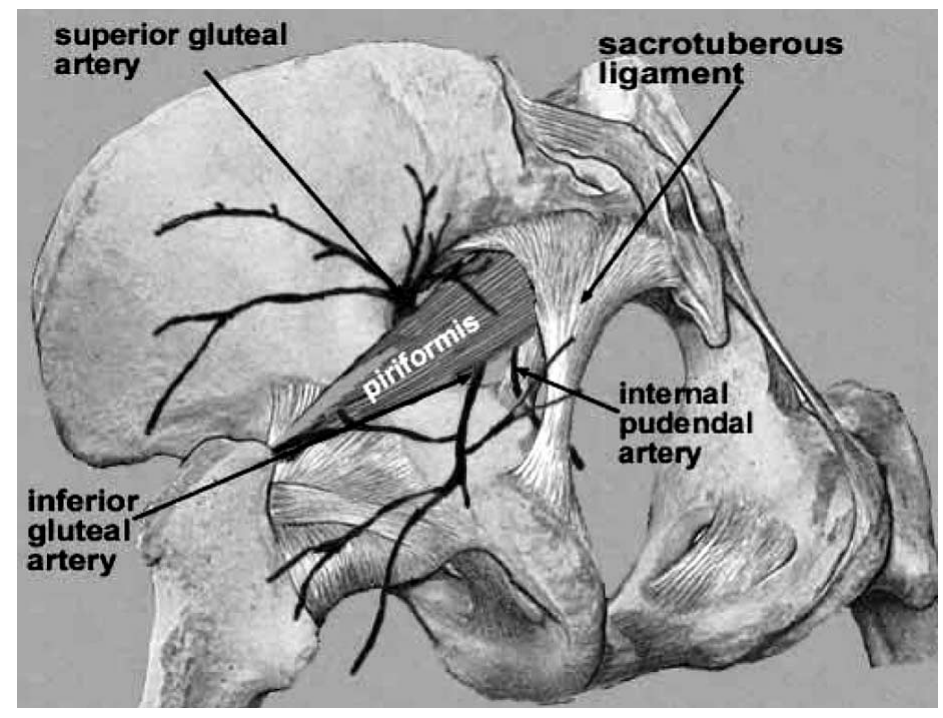

The inferior gluteal artery is the larger terminal branch of the anterior division of internal iliac artery and principally supplies the buttock and thigh. It descends posteriorly, anterior to the sacral plexus and piriformis muscle but posterior to the internal pudendal artery. It passes between the first and second or second and third sacral anterior spinal nerve rami, then between the piriformis muscle and ischiococcygeus muscle. It runs through the lower part of the greater sciatic foramen to reach the gluteal region (Fig. 1). The artery runs inferiorly between the greater trochanter and ischial tuberosity with the sciatic and posterior femoral cutaneous nerves deep to gluteus maximus muscle. It continues down the thigh, supplying the skin and anastomosing with branches of the perforating arteries. The inferior gluteal and internal pudendal arteries often arise as a common stem from the internal iliac, sometimes with the superior gluteal artery. Inside the pelvis the inferior gluteal artery gives branches to piriformis, ischiococcygeus and iliococcygeus muscles. Occasionally, it contributes to the middle rectal arterial supply and, in male, supplies vessels to the seminal vesicles and prostate (Standring, 2005).

The superior gluteal artery is the largest branch of the internal iliac artery and effectively forms the main continuation of its posterior division. It runs posteriorly between the lumbosacral trunk and the first sacral ramus or between the first and second rami, then

Fig. 1. Normal arterial pattern of gluteal region 
turns slightly inferiorly leaving the pelvis by the greater sciatic foramen above piriformis muscle and dividing into superficial and deep branches (Fig. 1). In the pelvis it supplies piriformis and obturator internus muscles and a nutrient artery to the ilium. The superficial branch enters the deep surface of gluteus maximus muscle. Its numerous branches supply the muscle and anastomose with the inferior gluteal artery branches while others perforate the tendinous medial attachment of the muscle to supply the skin over the sacrum where they anastomose with the posterior branches of the lateral sacral arteries. The deep branch of the superior gluteal atery passes between gluteus medius muscle and bone, soon dividing into superior and inferior branches. The superior branch skirts the superior border of gluteus minimus muscle to the anterior superior iliac spine and anastomoses with the deep circumflex iliac artery and the ascending branch of the lateral circumflex femoral artery. The inferior branch runs through gluteus minimus muscle obliquely, supplies it and gluteus medius muscle and anastomoses with the lateral circumflex artery. A branch enters the trochanteric fossa to join the inferior gluteal artery and ascending branch of the medial circumflex femoral artery while other branches run through gluteus minimus muscle to supply the hip joint (Standring).

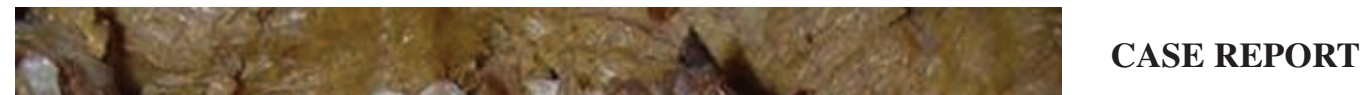

During routine dissection of the right gluteal region of an adult male cadaver, we observed a rare variation of absence of inferior gluteal artery compensated by a branch coming from superior gluteal artery. The origin of superior gluteal artery was different from nor$\mathrm{mal}$; it came from anterior division of internal iliac artery (Fig. 2).

The superior gluteal artery took origin from the anterior division of internal iliac artery, passed through the greater sciatic foramen and appeared in the gluteal region above the piriformis muscle. The artery divided into superficial and deep branches. The superficial branch passed between the gluteus medius and maximus muscles and supplied both of them, it also gave an anomalous branch which replaced the inferior gluteal artery and accompanied the inferior gluteal nerve. The anomalous branch supplied the adjacent muscles and took part in cruciate and trochanteric anastomoses. There was no inferior gluteal artery in the specimen.

\section{DISCUSSION}

Anatomical variations of gluteal region are well documented but the absence of inferior gluteal artery has never
Fig. 2. Absence of inferior gluteal artery compensated by an anomalous branch arising from superior gluteal artery. SGA. Superior gluteal artery; AB. Anomalous branch; IGN. Inferior gluteal nerve; P. Piriformis muscle; GM. Gluteus maximus muscle. 
been reported in the literature. Primarily, the gluteal region contains the diverging elements derived from the sacral plexus and internal iliac vessels. According to Bergman et al., (1988) the inferior gluteal artery may form a common trunk with the superior gluteal artery, it may be doubled and may join the obturator artery.

According to Bergman et al., the internal iliac artery may give branches without dividing into anterior posterior divisions and branches of the anterior and posterior divisions of the internal iliac artery may exchange origins.

The axial artery (sciatic artery) is the major arterial supply to the lower limb bud at an early embryological stage. It primarily originates from the dorsal root of the umbilical artery. After the $22 \mathrm{~mm}$ embryological stage, the sciatic artery involutes and the femoral artery system develops as the major inflow source to the lower limb. In the adult, remnants of the sciatic artery persist as the proximal portion of the inferior gluteal artery, the popliteal and fibular arteries (Standring). In the present case the sciatic artery has persisted as the proximal portion of the superior gluteal artery.

Construction of any graft or flap requires very accurate knowledge about the vascular supply. The ramification of superficial branch of superior gluteal artery is used to construct skin flaps. In the buttock it is commonly known that the superior gluteal artery separates into two main branches, namely the superficial and deep branches. According to Kida et al., (1992) the superficial branch of the superior gluteal artery constantly divides into two main branches, which are called the ascending and transverse branches. Of the ascending and transverse branches, one or both usually give off at least one well developed division running on the undersurface of the gluteus maximus muscle $(98.2 \%)$. This division, which is called the intermediate branch in their study, generally reaches the superior edge of the muscle giving off only a couple of muscular branches and pierces the muscle and its deep fascia to supply skin $(83.6 \%)$. The authors have investigated 56 sides of 33
Japanese cadavers to see the ramification of the superficial branch of the superior gluteal artery. In the current manuscript the anomalous branch originated from the intermediate branch and replaced the inferior gluteal artery.

Ischemic buttock claudication is generally due to lesions of the common iliac or internal iliac vessels, especially if the collateral circulation is compromised (Hassen-Khodja et al., 1987). However, buttock claudication can also be caused by isolated stenosis of the superior gluteal artery in the absence of atheromatous involvement of the other arteries (Batt et al., 1997, Cook \& Dyet 1990). The observation of superior gluteal artery stenosis in the absence of atheromatous disease suggests the existence of an anatomic cause, and in particular arterial compression at the level of the suprapiriformis canal. In a study by Bouillanne et al., (1999) anatomic, angiographic, and $\mathrm{CT}$ findings all revealed the intimate relations between the superior gluteal artery and the greater sciatic notch; during its change in direction, the artery is pressed against the bony surface by the fibromuscular structures and the piriformis muscle, which form a true osseofibromuscular trap. Moreover, sagittal CT reconstructions demonstrated arterial calcifications at this level, whereas no such lesions were observed immediately upstream or downstream. Anatomopathologic study revealed the possibility of elective stenosis at this point, and demonstrated that the occluding lesion differs from classical atheroma. Along its course in the suprapiriformis canal, the superior gluteal artery is thus susceptible to stenosis involving specific histologic modifications suggesting elective alteration of the arterial wall due to repeated trauma. Depending on the extent of collateral circulation that may differ from one patient to another, this trap can lead to the development of functional signs (Jutiano et al., 1994). "Entrapment" of the superior gluteal artery should be suspected in patients who present with isolated buttock claudication despite otherwise normal vascular investigations. In the cases like the present article, if the superior gluteal artery is compressed, the blood supply to the gluteus maximus muscle will be diminished since the inferior gluteal artery is absent.

REDDY, S.; RAMANA, V. V. \& RAO, M. Ausencia de la arteria glútea inferior: Una rara observación. Int. J. Morphol., 25(1):95-98, 2007.

RESUMEN: La región glútea es una importante área anatómica y clínica, la cual contiene músculos y vitales elementos neurovasculares. Estos últimos son importantes por razones clínicas y morfológicas. En este trabajo describimos un raro caso de ausencia de la arteria glútea inferior. Encontramos también que la arteria glútea superior tenía su origen en la división anterior de la arteria iliaca interna. Las estructuras irrigadas normalmente por la arteria glútea inferior estaban irrigadas por una rama que se originaba de la arteria glútea superior. Son discutidos el desarrollo y el significado clínico de esta variación anatómica.

PALABRAS CLAVE: Arteria iliaca interna; Arteria glútea inferior; Arteria glútea superior; Variación anatómica. 


\section{REFERENCES}

Batt, M.; Desjardin, T.; Rogopoutos, A.; Hassen-Khodja \& Le Bas, P. Buttock claudication from isolated stenosis of the gluteal artery. J. Vasc. Surg., 25:584-6, 1997.

Bergman, R. A.; Thomson, S. A.; Afifi, A. K. \& Saadesh F. A. Compendium of human anatomic variations. Urban \& Schwarzenberg, Baltimore, Munich, 1988. p. 84.

Bouillanne, P. J.; Batt, M.; Hassen-Khodja, R.; Declemy, S. \& Pittaluga P. Anatomic bases for compression of the superior gluteal artery at the level of the gluteal canal. Surg. Radiol. Anat., 21:309-12, 1999.

Cook, A. M. \& Dyet, J. F. Case report: Percutaneous angioplasty of the superior gluteal artery in the treatment of buttock claudication. Clin. Radiol., 41:63-5, 1990.

Hassen-Khodja, R.; Batt, M.; Michetti, C. \& Le Bas, P. Radiologic anatomy of the anastomotic systems of the internal iliac artery. Surg. Radiol. Anat., 9:135-40, 1987.

Jutiano, P. J.; Bosse, M. J. \& Edwards, K. J. The superior gluteal artery in complex acetabular procedures. A cadaveric angiographic study. J. Bone Joint Surg., 76A:244-8, 1994.

Kida MY, Takami Y and Ezoe K. The ramification of the superficial branch of the superior gluteal artery. Anatomical basis of a new gluteus maximus myocutaneous flap. Surg Radiol Anat., 14:319-23, 1992.

Standring, S. Gray's Anatomy. $39^{\text {th }}$ edn. Elsevier Churchil Livingstone, 2005. pp.1361, 1362, 1547, 1548.
Correspondence to:

Venkata Ramana Vollala, Department of Anatomy, Melaka Manipal Medical College (Manipal Campus), International Centre for Health Sciences, Manipal-576104,

Karnataka State - INDIA

Phone: 91-820-2922642

Fax: 91-820-2571905

Email: ramana.anat@gmail.com

Received: 06-10-2006

Accepted: 22-12-2006 